\title{
Cost-effectiveness of antibiotic treatment of uncomplicated urinary tract infection in women: a comparison of four antibiotics
}

\author{
Susannah Sadler, BSc, MSc ${ }^{1,2 *}$, Michael Holmes, BSc ${ }^{3}$, Shijie Ren, BSc, MPhil, PhD ${ }^{4}$, \\ Stephen Holden, MSc, BMedSci, BMBS ${ }^{5}$, Swati Jha, MD, FRCOG ${ }^{6}$, \\ Praveen Thokala, MASc, PhD
}

${ }^{1}$ Research Associate, School of Health and Related Research, University of Sheffield, Sheffield, UK; ${ }^{2}$ Research Fellow, University of Exeter Medical School, University of Exeter, Exeter, UK; ${ }^{3}$ Research Associate, School of Health and Related Research, University of Sheffield, Sheffield, UK; ${ }^{4}$ Research Associate, School of Health and Related Research, University of Sheffield, Sheffield, UK; ${ }^{5}$ Consultant Microbiologist, Department of Medical Microbiology, Nottingham University Hospitals NHS Trust, QMC Campus, Nottingham, UK; ${ }^{6}$ Consultant Gynaecologist, Gynaecology, Sheffield Teaching Hospitals NHS Foundation Trust, Sheffield, UK; ${ }^{7}$ Research Fellow, School of Health and Related Research, University of Sheffield, Sheffield, UK

*For correspondence: s.e.sadler@ exeter.ac.uk

Competing interests: The authors declare that no competing interests exist.

Received: 06 March 2017 Accepted: 22 March 2017

Published: 20 September 2017

(C) This article is Open Access: CC BY license (https:// creativecommons.org/licenses/ by/4.0/)

Author Keywords: urinary tract infection, antibiotic, costeffectiveness, resistance, primary care

Copyright (C) The Authors 2017; DOI:10.3399/

bjgpopen17X101097

\section{Abstract}

Background: Urinary tract infections (UTIs) are one of the most common reasons for women to attend primary care. There are four different antibiotics currently recommended in England for treatment of uncomplicated UTI but little evidence on their comparative cost-effectiveness.

Aim: To assess the relative cost-effectiveness of the four antibiotics currently recommended in England for treatment of uncomplicated UTI in adult women.

Design \& setting: A cost-effectiveness model in adult women with signs and symptoms of uncomplicated UTI in primary care in England treated with fosfomycin, nitrofurantoin, pivmecillinam, or trimethoprim.

Method: A decision tree economic model of the treatment pathway encompassed up to two rounds of treatment, accounting for different resistance levels. End points included recovery, persistence, pyelonephritis, and/or hospitalisation. Prescription, primary and secondary care treatment, and diagnostic testing costs were aggregated. Cost-effectiveness was assessed as cost per UTI resolved.

Results: Trimethoprim $200 \mathrm{mg}$ twice daily (for 3 or 7 days) was estimated to be the most costeffective treatment ( $f 70$ per UTI resolved) when resistance was $<30 \%$. However, if resistance to trimethoprim was $\geq 30 \%$, fosfomycin $3 \mathrm{~g}$ once became more cost-effective; at resistance levels of $\geq 35 \%$ for trimethoprim, both fosfomycin $3 \mathrm{~g}$ once and nitrofurantoin $100 \mathrm{mg}$ twice daily for 7 days were shown to be more cost-effective.

Conclusion: Knowing local resistance levels is key to effective and cost-effective empirical prescribing. Recent estimates of trimethoprim resistance rates are close to $50 \%$, in which case a single $3 \mathrm{~g}$ dose of fosfomycin is likely to be the most cost-effective treatment option.

\section{How this fits in}

Four different antibiotics are currently recommended for treatment of uncomplicated urinary tract infection (UTI) in adult women in England. It is usual practice to treat empirically at first presentation, 
but no studies to date have compared the relative cost-effectiveness of these treatments, so there is little to guide clinicians in their prescribing choice. The results of this study will help guide clinicians faced with decisions about empirical prescribing, to choose the most cost-effective option, especially in the context of local knowledge of resistance levels.

\section{Introduction}

UTIs are one of the most common reasons for women to attend primary care, and are likely to affect at least half of all women in their lifetime. ${ }^{1}$ In England in 2011, 14\% of antibiotic prescriptions for community-acquired infections were for UTI. ${ }^{2}$ Nitrofurantoin, a recommended first-line UTI treatment in England with no other recommended use, was prescribed more than 2.3 million times in 2015. ${ }^{3}$

For women with suspected uncomplicated UTI, Public Health England (PHE) recommends firstline treatment with nitrofurantoin, trimethoprim, or pivmecillinam. Fosfomycin or pivmecillinam are indicated where resistance risk is higher. ${ }^{4}$ In most cases, empirical treatment without urine culture is recommended and, as a result, the causative organism and its antimicrobial susceptibility are unknown. In practice, trimethoprim prescribing is still very common, despite some evidence of high levels of resistance. Although nitrofurantoin prescribing is still increasing, ${ }^{5}$ actual prescribing practice varies considerably between local areas. ${ }^{6}$

Antibiotic resistance is a key threat to public health; good prescribing practice is essential to reduce the spread of resistance. ${ }^{6}$ The aims of antibiotic prescribing should be to ensure treatment is effective, while minimising cost and reducing 'collateral damage' such as the emergence of multidrug resistant pathogens. As such, a good understanding of the effectiveness and cost-effectiveness of the drug, as well as national and local resistance levels, are necessary to aid decision making in primary care.

For clinical decision making, in which several relevant treatments options are recommended, it is important to understand the comparative efficacy and cost-effectiveness of all options. Although clinical trials to date have made direct comparisons between treatments, network meta-analyses (NMAs - allowing direct and indirect treatment comparisons) are needed in order to understand how the different treatments compare. Two previous meta-analyses of treatments in uncomplicated UTI have been undertaken, 7,8 but neither includes clinical outcomes for all the treatments currently recommended by PHE for uncomplicated UTI in England, and neither extends its findings to costeffectiveness analysis. This study aimed to compare the effectiveness and cost-effectiveness of these treatments and to explore the effect of changing resistance levels to trimethoprim.

\section{Method}

\section{Model structure}

The model was set in the context of the NHS in England. It was based on a decision tree model (Figure 1) developed by McKinnell et al, ${ }^{9}$ updated to include UK-specific costs. The pathway was checked by specialist clinicians.

In the model, patients were prescribed an antibiotic treatment regimen at their first GP appointment. The infection responded or failed to respond to treatment, depending on whether bacteria were resistant or susceptible to the antibiotic. Persistence of symptoms resulted in a repeat GP visit and second prescription. A potential consequence of persistent infection was pyelonephritis, treated either in hospital or primary care, in line with UK practice. It was assumed that all patients treated in hospital had a follow-up outpatient visit, and that all patients treated for a second time in primary care for either persistent UTI or pyelonephritis switched to a different antibiotic for their second course of treatment, in line with PHE guidance. ${ }^{4}$

Model timings were 9 days for the initial treatment round, followed by the weighted average of follow-up periods in the trials used for effectiveness data:

- 7days for second-round treatment if in primary care; or

- 5 days if in hospital (based on a recent UK study) ${ }^{10}$ plus 2 days of outpatient treatment for pyelonephritis. 


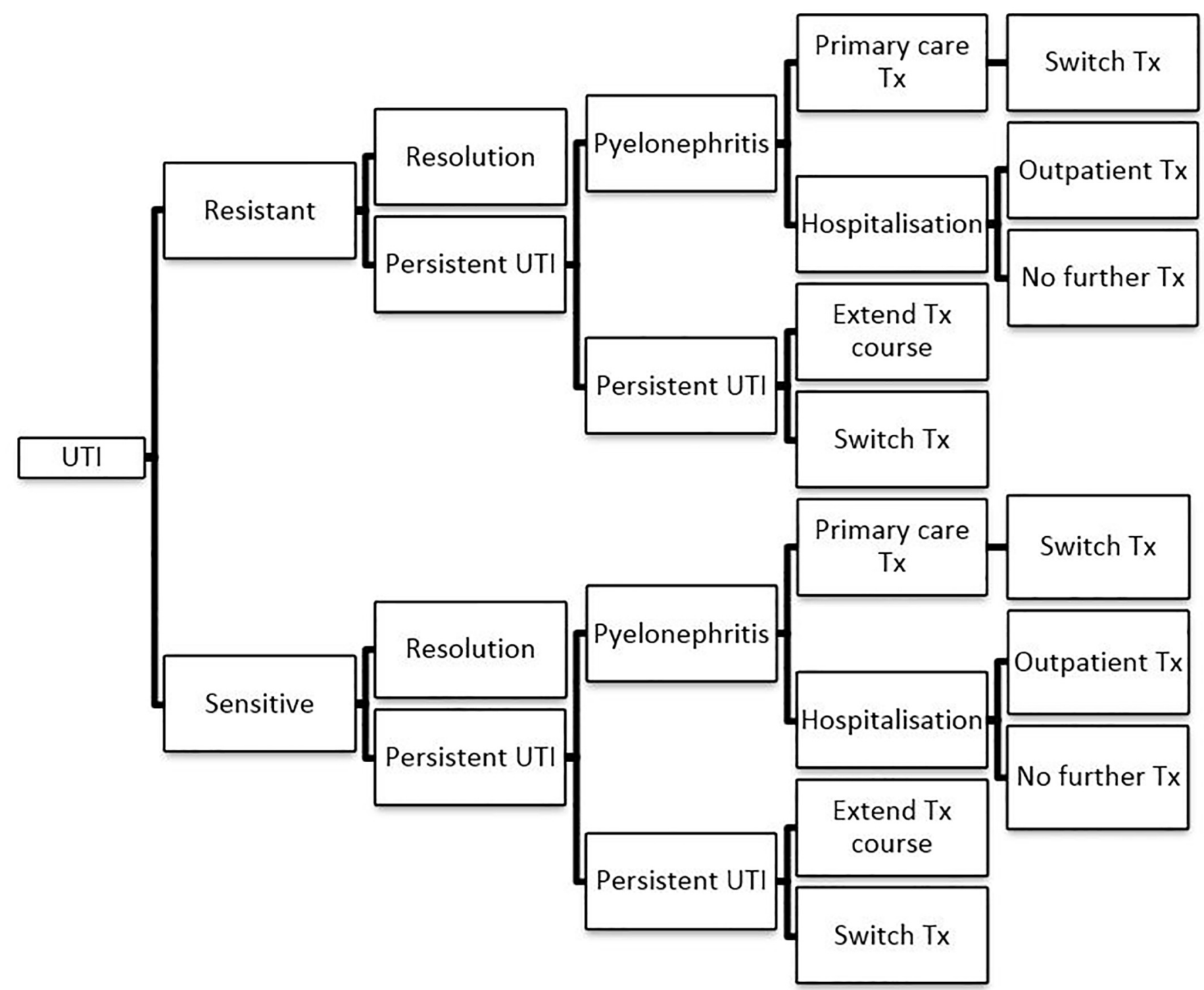

Figure 1. Model pathway. Tx = treatment. UTI = urinary tract infection.

This gave a total of 16 days. After two treatment courses all patients were assumed to have achieved cure.

\section{Clinical effectiveness}

Clinical cure rates were informed by a systematic review and NMA of studies in adult women with signs and symptoms of uncomplicated UTI (Appendix 1). The systematic review identified 11 studies that formed a connected evidence network used in the NMA (Figure 2). ${ }^{11-21}$ The studies covered nine treatment regimens:

- nitrofurantoin 50 mg four times a day for 7 days;

- nitrofurantoin modified release (MR) 100 mg twice daily for 7 days;

- nitrofurantoin $100 \mathrm{mg}$ four times a day for 3 days;

- pivmecillinam 200 mg three times a day for 7 days; 


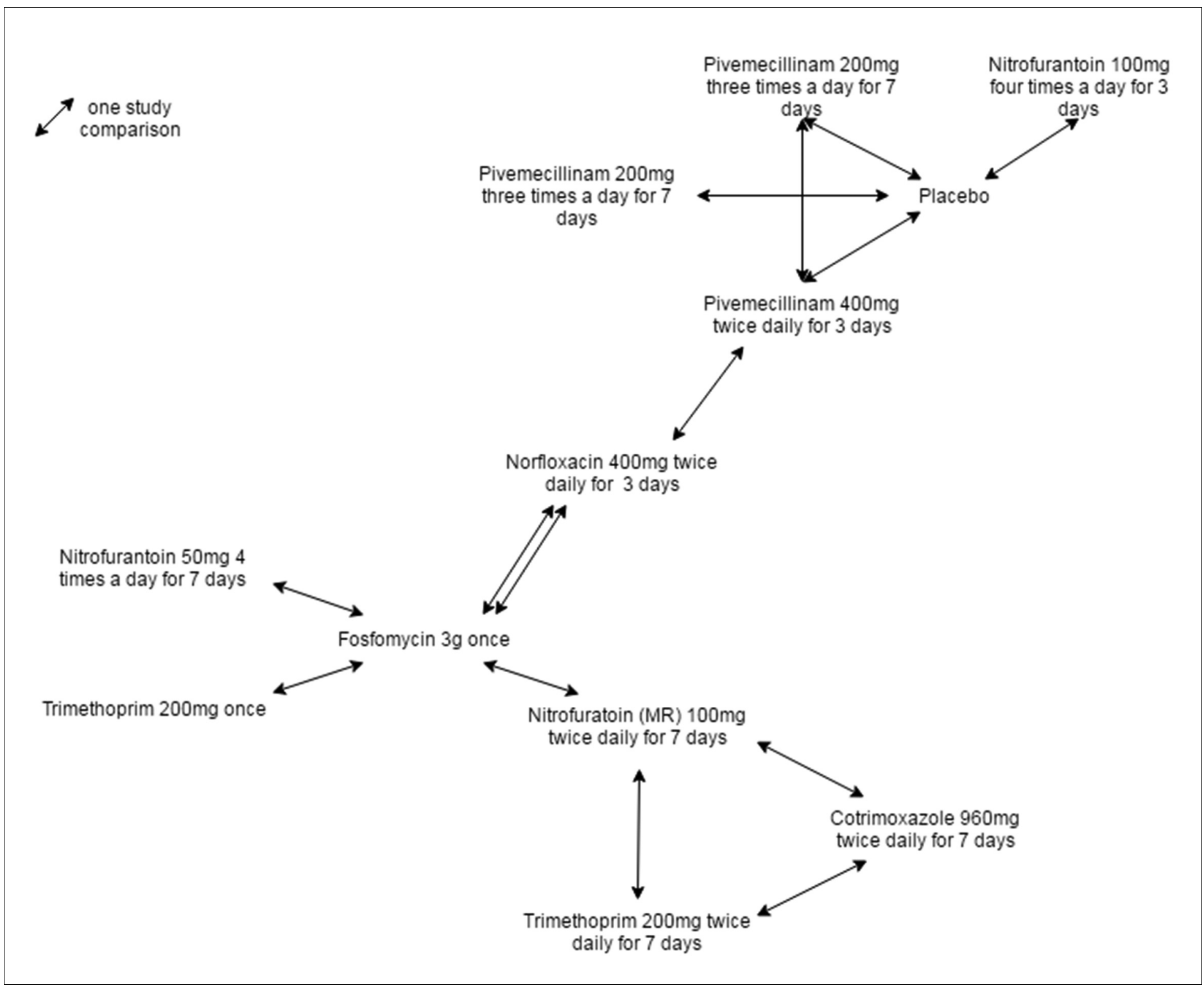

Figure 2. Network of trials identified in the systematic review and included in the network meta-analysis to estimate relative effectiveness of different treatment regimens.

- pivmecillinam $400 \mathrm{mg}$ twice daily for 3 days;

- pivmecillinam $200 \mathrm{mg}$ twice daily for 7 days;

- trimethoprim $200 \mathrm{mg}$ twice daily for 7 days;

- trimethoprim $200 \mathrm{mg}$ once; and

- fosfomycin $3 \mathrm{~g}$ once.

A random (treatment) effects model with a logit link function was used to allow for heterogeneity in treatment effects between studies. The model assumed a fixed (that is, unconstrained) baseline effect in each study so that treatment effects were estimated within study and combined across studies. The NMA model fitted the data well, with a total residual deviance of 20.47 being close to the number of data points included in the analysis $(n=21)$. The between-study standard deviation was estimated to be 0.21 ( $95 \%$ credible interval $=0.01$ to 0.68 ), implying mild heterogeneity in treatment effects between studies. Clinical cure rates for each of these regimens derived from the NMA are reported in Table 1. 
Table 1. Results of the network meta-analysis.

\begin{tabular}{|c|c|c|c|c|c|c|}
\hline & & esults of NM & IA of 11 RCTs & $\begin{array}{l}\text { Model paramet } \\
\text { NMA using N }\end{array}$ & $\begin{array}{l}\text { rs derived from } \\
\text { Nulty et } \mathrm{al}^{22}\end{array}$ & \\
\hline & $\begin{array}{l}\text { Odds } \\
\text { ratio }\end{array}$ & $95 \% \mathrm{Cl}$ & $\begin{array}{l}\text { Posterior mean cure } \\
\text { rate, } \%\end{array}$ & $\begin{array}{l}\text { Resistant cure } \\
\text { rate, \% }\end{array}$ & $\begin{array}{l}\text { Sensitive cure } \\
\text { rate, \% }\end{array}$ & $\begin{array}{c}\text { Resistance rate from ECO- } \\
\text { SENS II, }{ }^{23} \%\end{array}$ \\
\hline Fosfomycin $3 \mathrm{~g}$ once & 1 & - & 84.2 & 53.1 & 84.3 & 0.5 \\
\hline $\begin{array}{l}\text { Nitrofurantoin } 50 \mathrm{mg} \text { four times a } \\
\text { day for } 7 \text { days }\end{array}$ & 0.82 & 0.30 to 2.18 & 79.9 & 50.3 & 79.9 & 0.0 \\
\hline $\begin{array}{l}\text { Nitrofurantoin (MR) } 100 \mathrm{mg} \text { twice } \\
\text { daily for } 7 \text { days }\end{array}$ & 1.15 & 0.55 to 2.56 & 85.0 & 53.6 & 85.0 & 0.0 \\
\hline $\begin{array}{l}\text { Nitrofurantoin } 100 \mathrm{mg} \text { four times a } \\
\text { day for } 3 \text { days }\end{array}$ & 0.34 & 0.06 to 2.05 & 62.4 & 39.3 & 62.4 & 0.0 \\
\hline $\begin{array}{l}\text { Pivmecillinam } 200 \mathrm{mg} \text { three times a } \\
\text { day for } 7 \text { days }\end{array}$ & 0.63 & 0.16 to 2.57 & 75.0 & 47.4 & 75.3 & 1.0 \\
\hline $\begin{array}{l}\text { Pivmecillinam } 400 \mathrm{mg} \text { twice daily for } \\
3 \text { days }\end{array}$ & 0.47 & 0.14 to 1.57 & 69.8 & 44.2 & 70.1 & 1.0 \\
\hline $\begin{array}{l}\text { Pivmecillinam } 200 \text { mg twice daily for } \\
7 \text { days }\end{array}$ & 0.69 & 0.17 to 2.78 & 76.2 & 48.2 & 76.5 & 1.0 \\
\hline $\begin{array}{l}\text { Trimethoprim } 200 \mathrm{mg} \text { twice daily for } \\
7 \text { days }\end{array}$ & 1.29 & 0.43 to 4.02 & 85.9 & 57.3 & 90.8 & 14.9 \\
\hline Trimethoprim 200 mg once & 0.31 & 0.06 to 1.38 & 61.1 & 40.8 & 64.7 & 14.9 \\
\hline
\end{tabular}

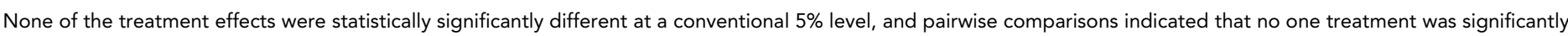
more effective than any other. $\mathrm{Cl}=$ credible interval. $\mathrm{MR}=$ modified release. $\mathrm{NMA}=$ network meta analyses. $\mathrm{RCT}=$ randomised controlled trial.

The ratio of resistant to sensitive cure rate (0.63) was applied to overall cure rates from the NMA to estimate sensitive and resistant cure rates for each regimen. This ratio was taken from a UK prospective cohort study that found statistically significant differences in clinical cure rates between those infected with trimethoprim-resistant and susceptible organisms, ${ }^{22}$ and was assumed to be consistent across all treatments. Resistance rates to each drug were taken from the ECO-SENS II study, $^{23}$ which provided UK-specific resistance rates for Escherichia coli only. Table 1 summarises the cure rates and resistance rates used in the base case.

\section{Other model parameters}

The GP appointment cost was taken from the Personal Social Services Research Unit's Unit Costs of Health and Social Care 2014. ${ }^{24}$ The dipstick test cost was taken from a Health Technology Assessment by Little et $a_{1}{ }^{25}$ and the Healthcare Resource Groups' national schedule of reference $\operatorname{costs}^{26}$ was used for the cost of pyelonephritis hospitalisation, pyelonephritis outpatient visits, and urine analysis tests. The cost of nitrofurantoin, trimethoprim, and pivmecillinam were taken from the British National Formulary, ${ }^{27}$ whereas the cost of fosfomycin was provided by the manufacturer since it is not listed in the BNF.

As in McKinnell et al $^{9}$ the authors assumed that $4 \%$ of those not achieving clinical cure at first treatment develop pyelonephritis, and $20 \%$ of those with pyelonephritis require hospitalisation. Model parameters are summarised in Table 2.

Analysis

The outcome was cost per UTI resolved. No incremental analysis was carried out as all treatments assessed are currently recommended for use in the NHS in England.

\section{Sensitivity analysis}

To account for uncertainty, probabilistic sensitivity analysis (PSA) was carried out using 2000 sets of model results. Parameters were sampled from the following distributions:

- beta (resistance rates);

- gamma (health service costs); and

- the posterior distribution of the NMA (clinical cure rates). 
Table 2. Model parameters, including costs and treatment pathways, used in the model

\begin{tabular}{|c|c|c|c|}
\hline Parameter & Type & Mean cost, $f$ & Source \\
\hline Fosfomycin $3 \mathrm{~g}$ once & Prescription & 4.86 & Profile Pharma $^{a}$ \\
\hline Nitrofurantoin $50 \mathrm{mg}$ four times a day for 7 days & Prescription & 13.93 & \multirow[t]{8}{*}{$B N F^{27}$} \\
\hline Nitrofurantoin (MR) 100 mg twice daily for 7 days & Prescription & 9.50 & \\
\hline Nitrofurantoin $100 \mathrm{mg}$ four times a day for 3 days & Prescription & 8.14 & \\
\hline Pivmecillinam 200 mg three times a day for 7 days & Prescription & 9.45 & \\
\hline Pivmecillinam 400 mg twice daily for 3 days & Prescription & 5.40 & \\
\hline Pivmecillinam, 200 mg twice daily for 7 days & Prescription & 6.30 & \\
\hline Trimethoprim 200 mg twice daily for 7 days & Prescription & 1.00 & \\
\hline Trimethoprim 200 mg once & Prescription & 0.07 & \\
\hline Pyelonephritis & Hospitalisation & 3992.00 & \multirow[t]{3}{*}{ National schedule of reference costs ${ }^{26}$} \\
\hline Pyelonephritis & Outpatient visit & 94.00 & \\
\hline Urine analysis & Test & 7.00 & \\
\hline GP appointment & Per patient contact (11.7 minutes) & 46.00 & PSSRU ${ }^{24}$ \\
\hline Dipstick test & Test & 0.40 & Little et $a^{25}$ \\
\hline \multicolumn{4}{|l|}{ Pathway } \\
\hline \multicolumn{2}{|l|}{ Risk of pyelonephritis if clinical cure not achieved, $\%$} & 4.00 & McKinnel et al ${ }^{9}$ \\
\hline \multicolumn{2}{|l|}{ Risk of hospitalisation if pyelonephritis, \% } & 20.00 & \\
\hline
\end{tabular}

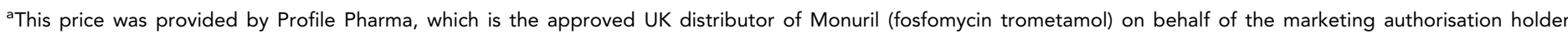

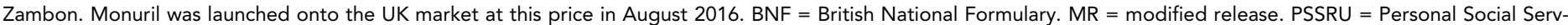
ices Research Unit. 


\section{Results}

\section{Probabilistic economic model results}

Central estimates from the PSA in terms of costs, health outcomes, and cost per UTI resolved are reported in Table 3. Trimethoprim $200 \mathrm{mg}$ twice daily for 7 days was estimated to be the most costeffective treatment regimen at $\mathrm{f} 70$ per UTI resolved, followed by fosfomycin $3 \mathrm{~g}$ once at $\mathrm{f} 78$ per UTI resolved. Trimethoprim $200 \mathrm{mg}$ twice daily for 7 days also had the highest probability of being the most cost-effective treatment (59\% of PSA runs).

Figure 3 shows the probabilistic average total cost and number of UTIs resolved per 1000 patients for each treatment regimen. A group of three treatments - trimethoprim $200 \mathrm{mg}$ twice daily for 7 days, fosfomycin $3 \mathrm{~g}$ once, and nitrofurantoin $100 \mathrm{mg}$ twice daily for 7 days - stood out as being most effective for resolution (approximately 850 cases resolved per 1000) and had the lowest total cost ( $£ 60000-f 70000$ ). Figure 3 illustrate the uncertainty around the central estimates of cost-effectiveness, showing the results of each of the 2000 probabilistic model runs for each treatment regimen.

\section{Deterministic sensitivity analysis}

Results are summarised in Table 3. Scenario A had the expected effect of reducing the apparent cost-effectiveness of nitrofurantoin relative to the other treatments. Scenario $B$ reduced the costeffectiveness for all treatments with increased resistance, as expected. In particular, the cost-effectiveness of trimethoprim reduced significantly: from a deterministic value of $f 69$ to $f 91$ per UTI resolved for trimethoprim $200 \mathrm{mg}$ twice daily for 7 days: this resulted in trimethoprim $200 \mathrm{mg}$ twice daily no longer being the most cost-effective treatment. Scenario $C$ reduced the cost-effectiveness of trimethoprim $200 \mathrm{mg}$ twice daily for 7 days and nitrofurantoin (MR) $100 \mathrm{mg}$ twice for 7 days, but trimethoprim $200 \mathrm{mg}$ twice daily was still shown to be the most cost-effective treatment (up from $£ 69$ to $£ 73$ per UTI resolved against a cost of $£ 100$ per UTI resolved for nitrofurantoin).

The threshold analysis on trimethoprim resistance showed that for resistance of $>25 \%$, trimethoprim $200 \mathrm{mg}$ twice daily for 7 days remained the most cost-effective option. However, at $30 \%$ resistance, fosfomycin $3 \mathrm{~g}$ once became more cost effective, and at resistance levels of $\geq 35 \%$ both fosfomycin $3 \mathrm{~g}$ once and nitrofurantoin (MR) $100 \mathrm{mg}$ twice daily for 7 days appeared to be more cost effective than trimethoprim $200 \mathrm{mg}$ twice daily.

Table 3. Probabilistic costs, health outcomes, and cost per UTI resolved per treatment regimen modelled

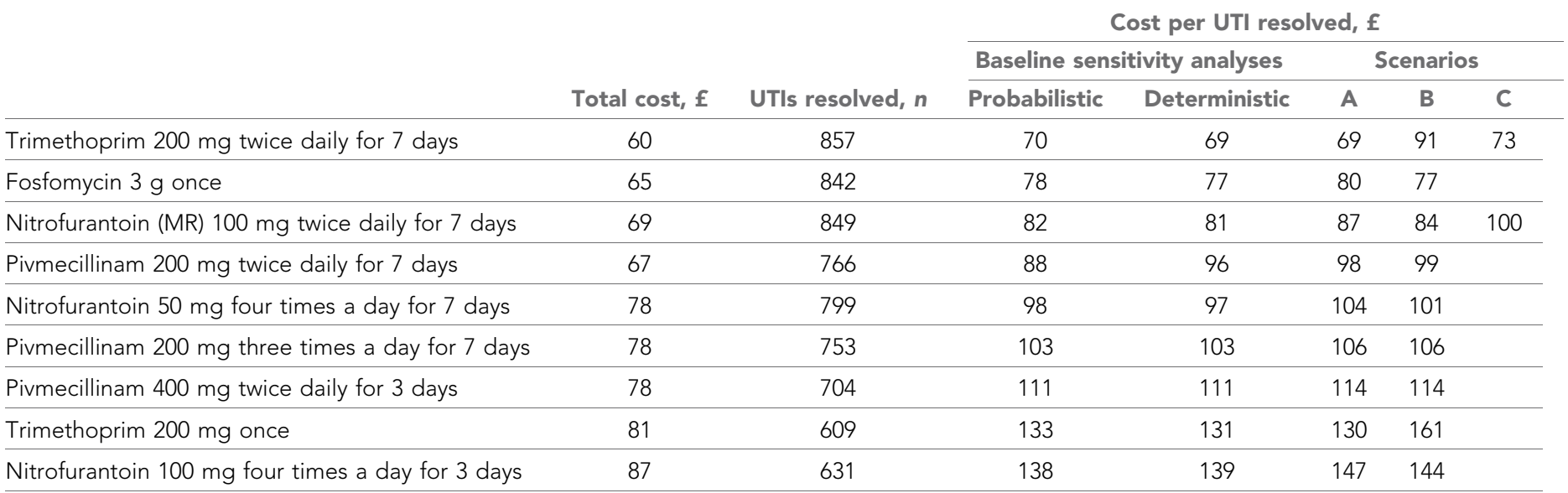

Note: treatments ordered by lowest cost per UTI resolved.

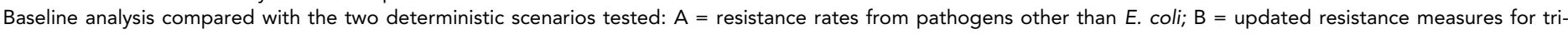

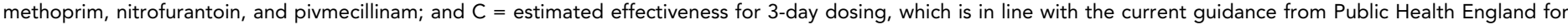
use of these treatments. MR = modified release. $\mathrm{UTI}=$ urinary tract infection. 

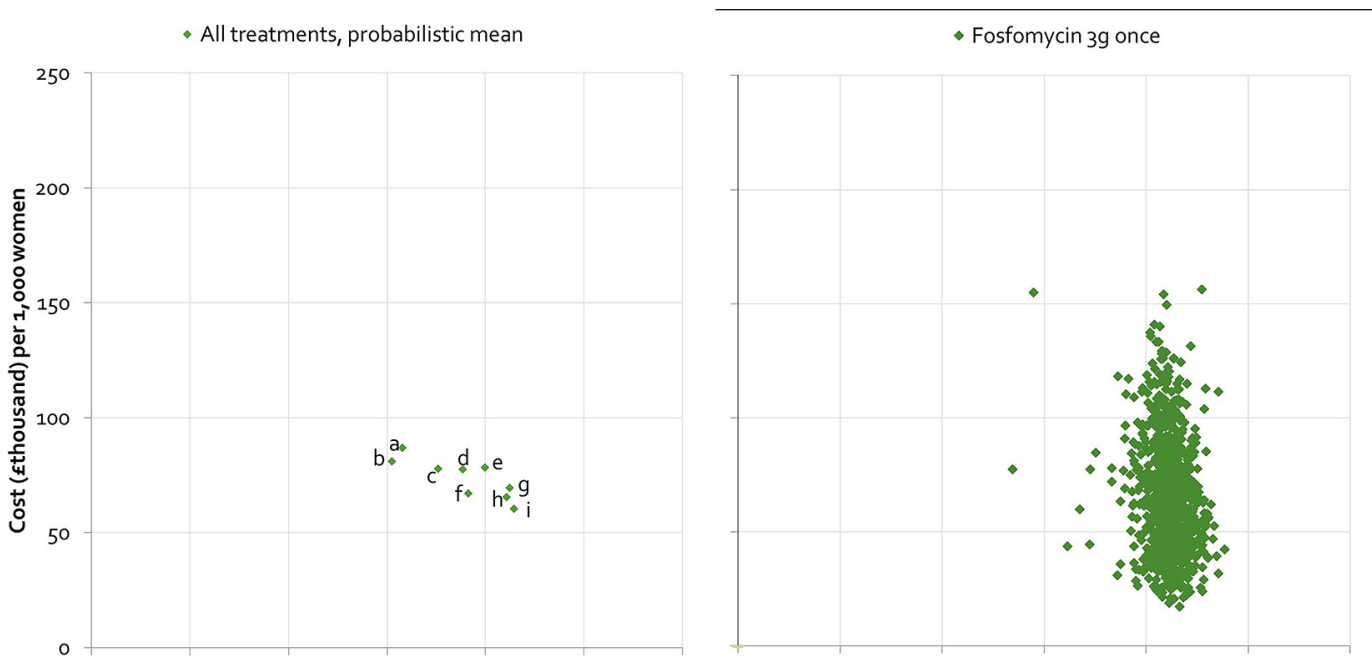

- Nitrofurantoin 10omg $4 \times$ daily, 3 days

Nitrofurantoin 5omg $4 \times$ daily, 7 days
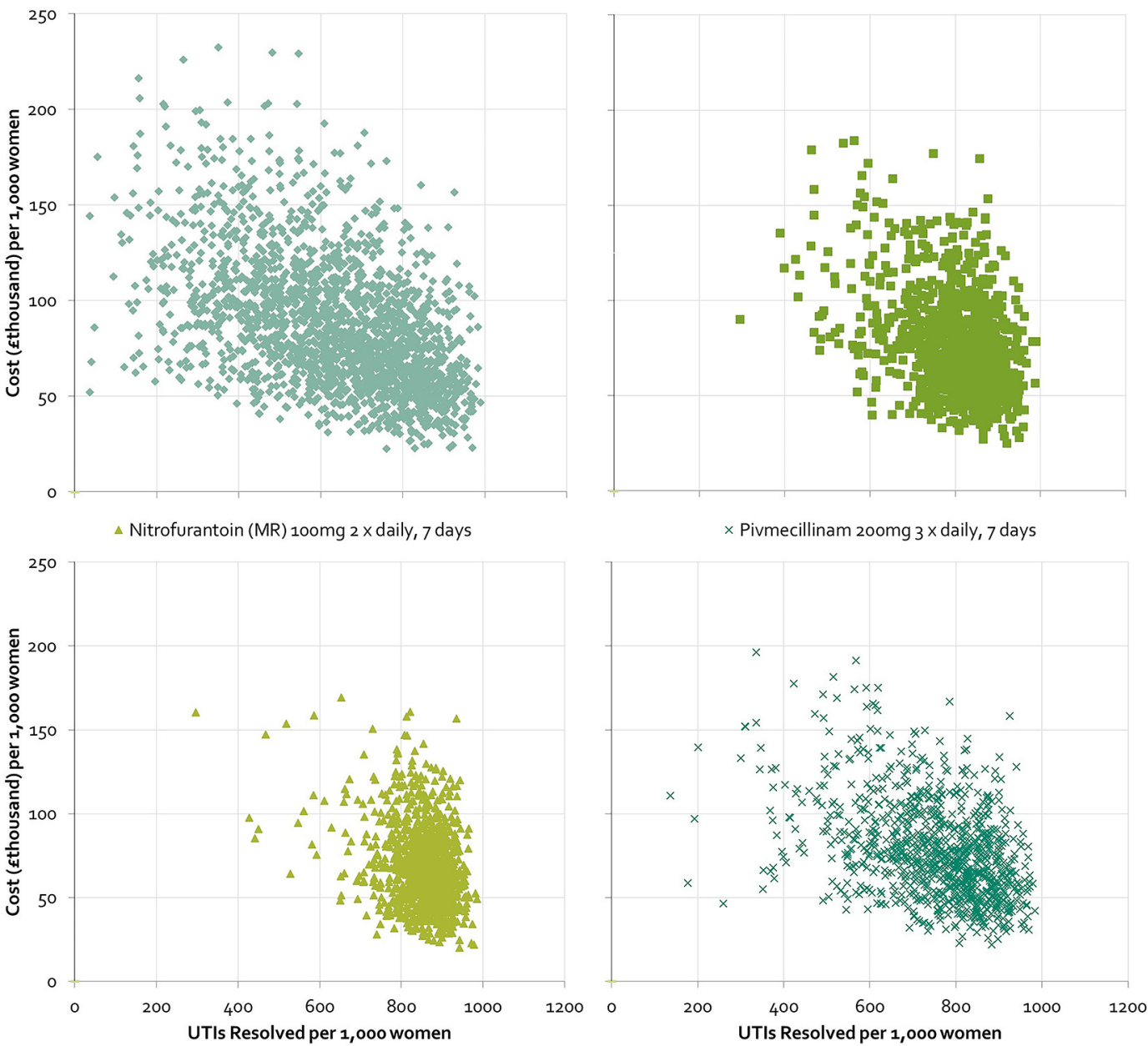


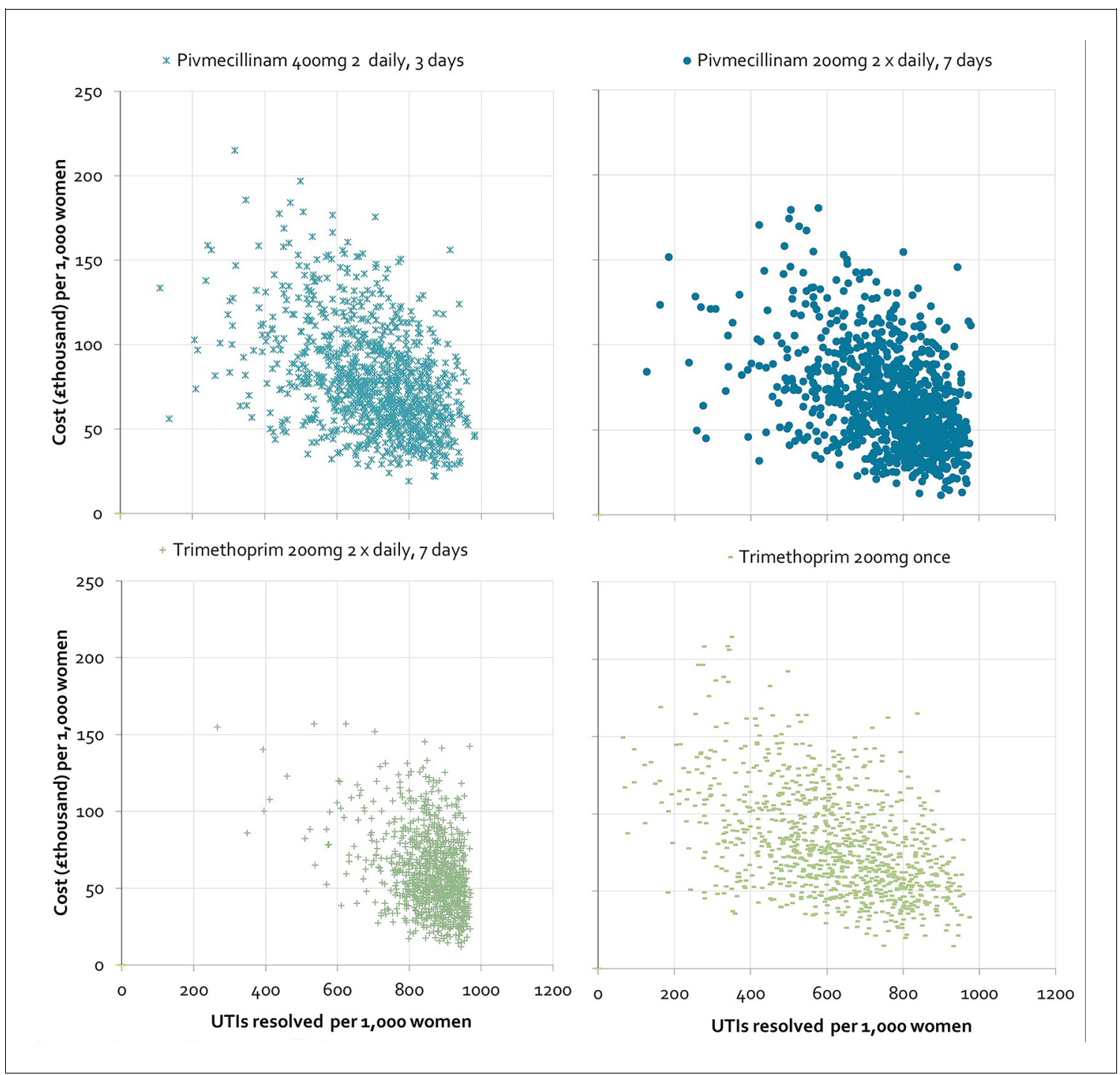

Figure 3. Cost-effectiveness plane comparing all treatment regimens.

\section{Discussion}

\section{Summary}

The highest clinical cure rate was estimated to be with trimethoprim $200 \mathrm{mg}$ twice daily for 7 days. In general, higher cure rates were seen with 7-day regimens compared with 3-day regimens, however, treatment effects were not statistically significantly different.

Trimethoprim $200 \mathrm{mg}$ twice daily for 7 days was estimated to be the most cost-effective treatment regimen, followed by fosfomycin $3 \mathrm{~g}$ once. In line with best practice for antimicrobial stewardship, 7-day trimethoprim prescriptions are now falling, with almost $50 \%$ of prescriptions being for the recommended 3-day courses. ${ }^{32}$ Due to lack of trial evidence, the authors estimated the impact of reducing the course length of both trimethoprim and nitrofurantoin from 7 to 3 days. This did not alter the fact that trimethoprim $200 \mathrm{mg}$ twice daily was the most cost-effective treatment but nitrofurantoin (MR) $100 \mathrm{mg}$ twice daily became less cost-effective than both pivmecillinam $200 \mathrm{mg}$ twice daily for 7 days and nitrofurantoin $50 \mathrm{mg}$ four times a day for 7 days.

The base case model results account only for resistance to $E$. coli. However, other species are known to have higher levels of resistance to all the antibiotics assessed. In particular, nitrofurantoin is non-effective against a number of Klebsiella, Enterobacter, and Proteus strains. When the authors 
accounted for resistance to other species, the cost-effectiveness was reduced (especially for nitrofurantoin) but the ranking of treatments was unaffected.

Recent work points to considerable increases in the resistance of common uropathogens. Kahlmeter et al observed increased rates of resistance of $E$. coli in uncomplicated UTI in the UK to nitrofurantoin, pivmecillinam, and trimethoprim. ${ }^{30}$ At this higher level of resistance, and even at resistance levels as low as 30\%, trimethoprim $200 \mathrm{mg}$ twice daily was no longer the most cost-effective treatment. Assuming fosfomycin resistance is unchanged (to date, it has been rarely prescribed in the UK and there is some evidence that resistance rates - at least to E. coli - remain stable, even in countries with systematic fosfomycin use), ${ }^{33}$ fosfomycin $3 \mathrm{~g}$ once would be the most costeffective option for empirical treatment, followed by nitrofurantoin (MR) $100 \mathrm{mg}$ twice daily for 7 days.

\section{Strengths and limitations}

There were several limitations in this analysis. There was a lack of evidence available to inform differential cure rates with resistant versus sensitive bacteria strains. Due to a lack of RCT evidence, the authors estimated the differential rates from the ratio of sensitive to resistant cure in a UK cohort study that investigated trimethoprim only, ${ }^{11}$ based on expert clinical opinion. The results of the study conformed to prior expectations: that is, that cure rates would be lower in matched patients infected with organisms resistant to the treatment antibiotic. The derivation also reflects the fact that clinical resolution occurs in a proportion of patients who were not treated (previous studies showed rates ranging from $25 \%$ to $42 \%),{ }^{12-14}$ and that when patients are treated with an antimicrobial agent to which the infecting uropathogen is resistant on laboratory testing, it is generally expected that cure rates will be higher than with placebo.

The study design had a number of important strengths: the context was the English health service; laboratory testing and clinical management were in accordance with established practice and national recommendations that are still broadly the same at present; and patients with host factors that could bias the data, such as structural abnormalities of the renal tract, pregnancy, and recurrent UTIs, were excluded.

\section{Comparison with existing literature}

Le and Miller ${ }^{34}$ carried out a similar analysis in a US setting, comparing trimethoprim-sulfamethoxazole (TMP-SMX - the recommended first-line treatment for uncomplicated UTI in women) with fluoroquinolones (recommended when resistance levels are $>10 \%$ ); subsequently, McKinnel et al compared nitrofurantoin to these two treatments, also in a US setting: increasing TMP-SMX resistance was shown to increase mean costs of UTI treatment such that when resistance to TMP-SMX exceeded $22 \%$, fluoroquinolones were the cheaper option, ${ }^{34}$ and that when fluoroquinolone resistance exceeded 12\%, nitrofurantoin was the least costly option. ${ }^{9}$ Similarly, the study presented here showed trimethoprim to be the most cost-effective option compared with the other treatments recommended in England, as long as resistance was $<30 \%$.

\section{Implications for research and practice}

Several pieces of additional evidence would enhance the authors' model estimates, were they available. Very few studies analysed both in vitro susceptibility and clinical response, meaning differential cure rates for sensitive and resistant strains had to be estimated. Similarly, recent, multicentre antimicrobial resistance surveillance data from all female patients with uncomplicated UTI, including those ordinarily treated empirically without sampling, would be very valuable.

Although this analysis confirmed that all four treatments that are currently recommended for uncomplicated UTI in England are effective in terms of efficacy and relative cost-effectiveness, trimethoprim $200 \mathrm{mg}$ twice daily for either 3 or 7 days appeared to be the preferable treatment. However, evidence of rapid increases in trimethoprim resistance in the UK, coupled with the potential for local-level variation, casts doubt on its cost-effectiveness in empirical treatment of uncomplicated UTI. Assuming resistance to fosfomycin has not increased since 2008, fosfomycin $3 \mathrm{~g}$ once appears to be the most cost-effective option for empirical treatment given the potentially high levels of trimethoprim resistance. 
The four drugs examined all have a relatively low propensity to cause Clostridium difficile infection and it is likely that acquired resistance to nitrofurantoin, pivmecillinam, and fosfomycin despite widespread global use for many years - has not readily emerged due to their rapid absorption and minimal impact on the human gastrointestinal tract flora. These properties make them ideal treatments for uncomplicated UTI.

The modelling estimates in this study suggest that fosfomycin $3 \mathrm{~g}$ once is likely to be the most cost-effective choice for first-time empirical treatment of uncomplicated UTI in adult women, unless trimethoprim resistance is believed to be $<30 \%$; when resistance exceeds $35 \%$, nitrofurantoin ( $\mathrm{m}$ [MR]) $100 \mathrm{mg}$ twice daily would also be a cost-effective choice.

\section{Funding}

This work was funded by Profile Pharma Ltd, a subsidiary of Zambon SpA.

\section{Provenance}

Freely submitted; externally peer reviewed.

\section{Acknowledgements}

We would like to acknowledge Gina Craig and Alex Black of Profile Pharma Ltd for input into the project, including providing the price of fosfomycin.

\section{References}

1. Turner $D$, Little $P$, Raftery $J$, et al. Cost effectiveness of management strategies for urinary tract infections: results from randomised controlled trial. BMJ 2010; 340:c346. doi: 10.1136/bmj.c346

2. Health Protection Agency. English National Point Prevalence Survey on Healthcare-associated Infections and Antimicrobial Use, 2011: Preliminary Data; 2012.

3. Powell-Smith A, Goldacre B. Nitrofurantoin (0501130R0). https://openprescribing.net/chemical/0501130R0/ (accessed 6 Sep 2017).

4. Public Health England. Management of infection guidance for primary care for consultation and local adaptation. London: PHE, 2015.

5. Public Health England. English Surveillance Programme for Antimicrobial Utilisation and Resistance (ESPAUR) 2010 to 2014: Report 2015. London: PHE, 2015.

6. National Institute for Health and Care Excellence. Antimicrobial stewardship: prescribing antibiotics. 2015. https://www.nice.org.uk/advice/ktt9 (accessed 6 Sep 2017).

7. Huttner A, Verhaegh EM, Harbarth $S$, et al. Nitrofurantoin revisited: a systematic review and meta-analysis of controlled trials. J Antimicrob Chemother 2015; 70(9): 2456-2464. doi: 10.1093/jac/dkv147

8. Knottnerus BJ, Grigoryan L, Geerlings SE, et al. Comparative effectiveness of antibiotics for uncomplicated urinary tract infections: network meta-analysis of randomized trials. Fam Pract 2012; 29(6): 659-670. doi: 10. 1093/fampra/cms029

9. McKinnell JA, Stollenwerk NS, Jung CW, et al. Nitrofurantoin compares favorably to recommended agents as empirical treatment of uncomplicated urinary tract infections in a decision and cost analysis. Mayo Clin Proc 2011; 86(6): 480-488. doi: 10.4065/mcp.2010.0800

10. Hsu CY, Fang HC, Chou KJ, et al. The clinical impact of bacteremia in complicated acute pyelonephritis. Am J Med Sci 2006; 332(4): 175-180. doi: 10.1097/00000441-200610000-00004

11. Boerema JB, Willems FT. Fosfomycin trometamol in a single dose versus norfloxacin for seven days in the treatment of uncomplicated urinary infections in general practice. Infection 1990; 18 Suppl 2(Suppl 2): S80S88. doi: 10.1007/BF01643433

12. Christiaens TC, De Meyere M, Verschraegen G, et al. Randomised controlled trial of nitrofurantoin versus placebo in the treatment of uncomplicated urinary tract infection in adult women. Br J Gen Pract 2002; 52 (482): 729-734.

13. Ferry SA, Holm SE, Stenlund H, et al. Clinical and bacteriological outcome of different doses and duration of pivmecillinam compared with placebo therapy of uncomplicated lower urinary tract infection in women: the LUTIW project. Scand J Prim Health Care 2007; 25(1): 49-57. doi: 10.1080/02813430601183074

14. Gupta K, Hooton TM, Roberts PL, et al. Short-course nitrofurantoin for the treatment of acute uncomplicated cystitis in women. Arch Intern Med 2007; 167(20): 2207-2212. doi: 10.1001/archinte.167.20. 2207

15. Harvard Davis R, O'Dowd TC, Holmes W, et al. A comparative double-blind randomised study of single dose fosfomycin trometamol with trimethoprim in the treatment of urinary tract infections in general practice. Chemotherapy 1990; 36(Suppl 1): 34-36. doi: 10.1159/000238814

16. Nicolle LE, Madsen KS, Debeeck GO, et al. Three days of pivmecillinam or norfloxacin for treatment of acute uncomplicated urinary infection in women. Scand J Infect Dis 2002; 34(7): 487-492. doi: 10.1080/ 00365540110080728

17. Rafalskiy V, Khodnevitch L, Malev I, et al. Randomised clinical trial of short-course norfloxacin vs single dose fosfomycin for uncomplicated UTI in region with 10 resistance level of uropathogenic E.coli to 
fluoroquinolone. 19th European Congress of Clinical Microbiology and Infectious Diseases; 16-19 May 2009; Helsinki, Finland: European Society of Clinical Microbiology and Infectious Diseases; 2009.

18. Reynaert J, Van Eyck D, Vandepitte J. Single dose fosfomycin trometamol versus multiple dose norfloxacin over three days for uncomplicated UTI in general practice. Infection 1990; 18(S2): S77-S79. doi: 10.1007/ BF01643432

19. Spencer RC, Moseley DJ, Greensmith MJ. Nitrofurantoin modified release versus trimetfaoprim or cotrimoxazole in the treatment of uncomplicated urinary tract infection in general practice. $J$ Antimicrob Chemother 1994; 33(suppl A): 121--129. doi: 10.1093/jac/33.suppl_A.121

20. Stein GE. Comparison of single-dose fosfomycin and a 7-day course of nitrofurantoin in female patients with uncomplicated urinary tract infection. Clin Ther 1999; 21(11): 1864-1872. doi: 10.1016/S0149-2918(00) 86734-X

21. Pienbroek E, Hermans J, Kaptein AA, et al. Fosfomycin trometamol in a single dose versus seven days nitrofurantoin in the treatment of acute uncomplicated urinary tract infections in women. Pharmacy World \& Science 1993; 15(6): 257-262. doi: 10.1007/BF01871127

22. McNulty CAM, Richards J, Livermore DM, et al. Clinical relevance of laboratory-reported antibiotic resistance in acute uncomplicated urinary tract infection in primary care. $J$ Antimicrob Chemother 2006; 58 (5): 1000-1008. doi: 10.1093/jac/dkl368

23. Kahlmeter G, Poulsen HO. Antimicrobial susceptibility of Escherichia coli from community-acquired urinary tract infections in Europe: the ECO.SENS study revisited. Int J Antimicrob Agents 2012; 39(1): 45-51. doi: 10.1016/j.ijantimicag.2011.09.013

24. Curtis L. Unit costs of health and social care 2014. Canterbury: Personal Social Services Research Unit, University of Kent, 2014.

25. Little $\mathrm{P}$, Turner $\mathrm{S}$, Rumsby $\mathrm{K}$, et al. Dipsticks and diagnostic algorithms in urinary tract infection: development and validation, randomised trial, economic analysis, observational cohort and qualitative study. Health Technol Assess 2009; 13(19): 1-73. doi: 10.3310/hta13190

26. Department of Health. Reference Costs 2013-14. London: DH, 2014.

27. British Medical Association. British National Formulary. https://www.bnf.org/products/bnf-online/ (accessed 21 Aug 2017).

28. Kahlmeter G. The ECO^SENS Project: a prospective, multinational, multicentre epidemiological survey of the prevalence and antimicrobial susceptibility of urinary tract pathogens-interim report. $J$ Antimicrob Chemother 2000; 46(Suppl A): 15-22. doi: 10.1093/jac/46.suppl_1.15

29. Kahlmeter $\mathrm{G}$. An international survey of the antimicrobial susceptibility of pathogens from uncomplicated urinary tract infections: the ECOmiddle dotSENS Project. J Antimicrob Chemother 2003; 51(1): 69-76. doi: $10.1093 / \mathrm{jac} / \mathrm{dkg028}$

30. Kahlmeter G, Åhman J, Matuschek E. Antimicrobial resistance of Escherichia coli causing uncomplicated urinary tract infections: a European update for 2014 and comparison with 2000 and 2008. Infect Dis Ther 2015; 4(4): 417-423. doi: 10.1007/s40121-015-0095-5

32. Hawker JI, Smith S, Smith GE, et al. Trends in antibiotic prescribing in primary care for clinical syndromes subject to national recommendations to reduce antibiotic resistance, UK 1995-2011: analysis of a large database of primary care consultations. J Antimicrob Chemother 2014; 69(12): 3423-3430. doi: 10.1093/jac/ dku291

33. Karageorgopoulos DE, Wang R, Yu X-h, et al. Fosfomycin: evaluation of the published evidence on the emergence of antimicrobial resistance in Gram-negative pathogens. J Antimicrob Chemother 2012; 67(2): 255-268. doi: 10.1093/jac/dkr466

34. TP Le, Miller LG. Empirical therapy for uncomplicated urinary tract infections in an era of increasing antimicrobial resistance: a decision and cost analysis. Clin Infect Dis 2001; 33(5): 615-621.

35. Lunn DJ, Thomas A, Best N, et al. WinBUGS - A Bayesian modelling framework: concepts, structure, and extensibility. Stat Comput 2000; 10(4): 325-337. doi: 10.1023/A:1008929526011 


\section{Appendix 1}

Systematic review inclusion/exclusion criteria

Population: women aged $>18$ years with signs and symptoms of uncomplicated UTI

Interventions: fosfomycin, trimethoprim, nitrofurantoin, pivmecillinam (those recommended for treatment of uncomplicated UTI by Public Health England).

Outcomes: UTI resolution, persistence, pyelonephritis development and health-related quality of life (HRQoL)

Exclusion criteria: no clinical response measure, study not in English, studys specifically of older people patients who were pregnant or had a catheter

\section{Search strategy}

Randomised controlled trial (RCT) and systematic review study search strategies

Database: Ovid MEDLINE® In-Process \& Other Non-Indexed Citations, Ovid MEDLINE®

Daily, Ovid MEDLINE ${ }^{\circledR}$, and Ovid OLDMEDLINE ${ }^{\circledR}<1946$ to Present>

\section{Search strategy:}

Population terms (1-6)

1. exp Urinary Tract Infections/

2. urinary tract infection\$.ab,ti.

3. uti.ab,ti.

4. acute cystitis.ab,ti.

5. Cystitis/

6. 1 or 2 or 3 or 4 or 5

Intervention terms (7-14)

7. Fosfomycin/

8. fosfomycin.ab,ti.

9. phosphonomycin.ab,ti.

10. phosphomycin.ab,ti.

11. monuril.ab,ti.

12. monurol.ab,ti.

13. 2N81MY12TE.rn.

14. 7 or 8 or 9 or 10 or 11 or 12 or 13

Population and intervention terms combined (15)

15. 6 and 14

Comparator terms (16-47)

16. Nitrofurantoin/

17. nitrofurantoin.ab,ti.

18. furadoine.ab,ti.

19. furantoin.ab,ti.

20. macrodantin.ab,ti. 
21. furadonine.ab,ti.

22. furadantine.ab,ti.

23. furadantin.ab,ti.

24. macrobid.ab,ti.

25. 927AH8112L.rn.

26. Trimethoprim/

27. trimethoprim.ab,ti.

28. proloprim.ab,ti.

29. trimpex.ab,ti.

30. monotrim.ab,ti.

31. triprim.ab,ti.

32. tmi.ab,ti.

33. tmp.ab,ti.

34. AN164J8Y0X.rn

35. Amdinocillin Pivoxil/

36. pivmecillinam.ab,ti.

37. amdinocillin.ab,ti.

38. selexid.ab,ti.

39. pivamdinocillin.ab,ti.

40. fl 1039.ab,ti.

41. fl-1039.ab,ti.

42. fl1039.ab,ti.

43. mecillinam.ab,ti.

44. penomax.ab,ti.

45. coactabs.ab,ti.

46. 1WAM1OQ30B.rn.

47. or/16-46

Population and comparator terms combined (48)

48. 6 and 47

Population and intervention OR population and comparator (49)

49. 15 or 48

\section{Excluded comparator (50-54)}

50. Trimethoprim-Sulfamethoxazole Combination/

51. Sulfamethoxazole.ab,ti.

52. sulphamethoxazole.ab,ti.

53. 50 or 51 or 52

54. 49 not 53 


\section{Search filter to identify RCTs (92-106)}

92. randomized controlled trial.pt.

93. controlled clinical trial.pt.

94. randomized controlled trials/

95. random allocation/

96. double blind method/

97. single blind method/

98. clinical trial.pt.

99. $\exp$ Clinical Trial/

100. (clin\$ adj25 trial\$).ti,ab.

101. ((singl\$ or doubl\$ or treb|\$ or tripl\$) adj25 (blind\$ or mask\$)).ti,ab.

102. placebos/

103. placebos.ti,ab.

104. random.ti,ab.

105. research design/

106. or/92-105

(Population and Intervention OR population and comparator) AND RCT filter (107)

107. 54 and 106

\section{Search results}

The searches identified 978 citations, of which 958 were excluded by title or abstract. Twenty full papers were reviewed. Seven were excluded due to having no clinical outcome measure. Of the remaining $13 \mathrm{RCTs}, 11$ formed a connected network of evidence and were used in the network meta analysis (NMA). A total of 3983 participants were randomised across the trials, with the mean age across the trials ranging from 21 to 48 years.

\section{Evidence synthesis}

Evidence on clinical cure rates for the different regimens was synthesised by NMA using a random (treatment) effects model, with a logit link function to allow for heterogeneity in treatment effects between studies. All analyses were implemented in WinBUGS. ${ }^{35}$ Results of the NMA are reported in terms of the odds ratios and $95 \%$ credible intervals relative to fosfomycin $3 \mathrm{~g}$, which was used as the reference intervention. Absolute estimates of clinical cure rates were estimated for each intervention by projecting the estimates of treatment effect ( $\log \mathrm{OR})$ from the NMA onto the fosfomycin $3 \mathrm{~g}$ clinical cure rates. 